\title{
ЭФФЕКТИВНЫЕ СИСТЕМЫ ОКАЗАНИЯ МЕДИЦИНСКОЙ ПОМОЩИ НА ПРИМЕРЕ РЕСПУБЛИКИ ТАТАРСТАН
}

\author{
Р. Ш. Сунгатов, Д. Р. Галиева \\ ООО «Корпоративные информационные рутины (КИР)», г. Казань
}

\begin{abstract}
Представлено принципи побудови економічно ефективних систем надання медичної допомоги на рівні регіону. Наведено приклади реально працюючих рішень, що довели свою ефективність і за допомогою закладеної в них вірної бізнес-логіки, дозволили домогтися значного підвищення якості медичних послуг.
\end{abstract}

В настоящее время все отрасли, в том числе медицина, движутся в направлении информатизации. Процесс этот небыстрый и дорогой, но выгоды от него должны быть велики.

Чего мы ждем от информатизации медицины? Предполагается, что благодаря информатизации медицинские услуги станут более адресными и доступными; эффективность диагностики и лечения вырастет; сроки ожидания медицинской помощи сократятся; лечебно-профилактические учреждения повысят качество планирования ресурсов; управление запасами лекарственных средств существенно улучшатся, а органы управления здравоохранением выйдут на более высокий уровень контроля за расходами и качеством оказания медицинских услуг.

Больницы являются наиболее дорогостоящими учреждениями здравоохранения, поэтому рациональное использование коечного фонда имеет большое значение. Простой койки в больницах не только сокращает объем стационарной помощи и ухудшает медицинское обслуживание населения в целом, но и вызывает значительные экономические потери.

Именно для этого сейчас в России и внедряются региональные системы управления здравоохранением. Координация деятельности каждого уровня учреждений осуществляется с помощью региональной системы управления здравоохранением «Диспетчерский центр», разработанной компанией “Корпоративные информационные рутины".

Одна из задач, которую решает «Диспетчерский центр», - координация деятельности лечебных учреждений различного уровня. Так, в систему заносится протокол лечения каждой болезни. Любому этапу лечения соответствует лечебное учреждение, которое выполняет свою задачу: предгоспитальную, госпитальную операционную, постгоспитальную. Каждая группа лечебных учреждений решает свои, строго определенные задачи. Например, кардиологический больной сначала обследуется в больнице второго уровня, затем направляется на высокотех- нологичный, далее на долечивание идет в другую больницу второго уровня, а по завершении отправляется в санаторий. Сформированный таким образом маршрут рассчитан на 30-40 дней - до полного восстановления и выхода на работу.

Таким образом, дорогостоящие койки высокотехнологичных центров заняты только одним операционным этапом, что значительно сокращает стоимость лечения и делает более доступными дорогостоящие операции большему количеству пациентов.

В целях эффективного использования средств и рационального использования сложной, дорогостоящей диагностической аппаратуры программный комплекс «Центральный архив медицинских изображений» (ДЦ.ЦАМИ) стал эффективным инструментом повышения качества и доступности медицинской помощи населению. ДЦ.ЦАМИ позволил сбалансировать нагрузку между медицинскими учреждениями всех уровней региона посредством оперативного обмена изображениями между всеми участниками лечебно-диагностического процесса и организации дистанционного консультирования.

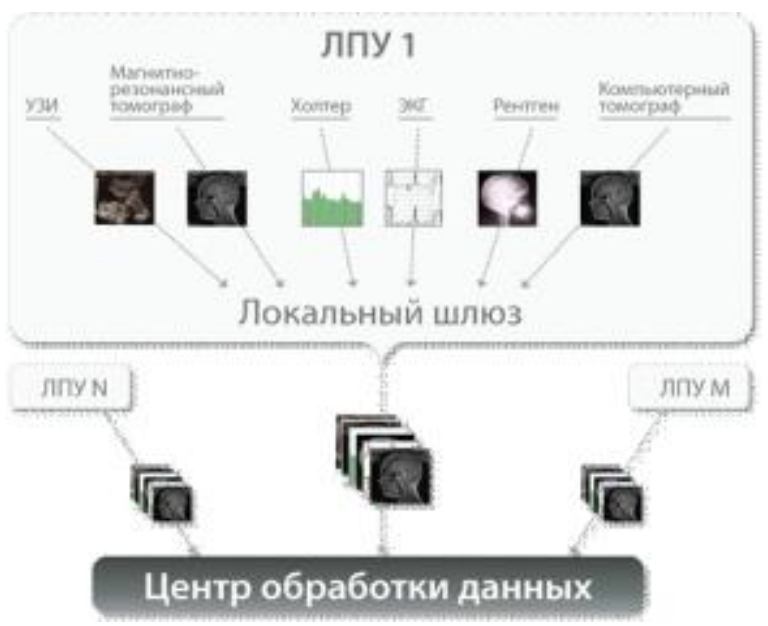

В него стекаются все снимки с подключенных аппаратов. Архив не только хранит снимки всех клиник региона, но и предоставляет возможность врачам

(c) Р. Ш. Сунгатов, Д. Р. Галиева 
просматривать эти снимки через обычный web-браузер на любом компьютере, где есть подключение к Интернет. При этом качество снимка не хуже, чем на самом аппарате, а врачу предлагается еще и набор инструментов для измерения, масштабирования и других операций над снимками. Эта подсистема сразу решает несколько проблем. При такой организации работы можно переходить на беспленочный режим работы. А это очень большая экономия средств! Снимки пациентов не теряются, доступны в любой момент.

Гарантированная доставка данных исследований в ДЦ.ЦАМИ достигается за счет установки в каждом лечебном учреждении локального шлюза. Этот сервер накапливает у себя данные, поступающие с медицинских аппаратов, и отправляет их на центральный сервер ДЦ.ЦАМИ. В условиях нестабильной работы сети передачи данных работа медицинского оборудования в лечебном учреждении не нарушается. При восстановлении связи медицинские изображения автоматически отправляются на центральный сервер.

В целях повышения качества и ускорения процесса лечения в системе есть возможность проводить удаленное консультирование врача-диагноста с необходимым специалистом. В случае, если диагност не может самостоятельно дать медицинское заключение по конкретному случаю, либо хочет дополнительно проконсультироваться относительно исследования, система предоставляет ему возможность оформить заявку на консультацию и получить оперативный ответ.

Многие модули системы, такие как центральный архив медицинских изображений и другие решения, реализованные посредством технологии $\mathrm{SaaS}$, стали «локомотивом» создания электронной медицинской карты пациента. Построенные на единой информационной платформе решения позволяют активно развивать кластерный подход информатизации здравоохранения, повышать эффективность управления здравоохранением и добиться значительных успехов в «проблемных» областях медицины, в тех, которые требуют наиболее пристального внимания. За счет организации целостного сквозного процесса управления здравоохранением и формализации процессов создан инструмент, способствующий снижению смертности от различных заболеваний, сокращению экономических затрат при повышении качества оказываемой медицинской помощи, достижению целевых показателей, запланированных региональными программами модернизации здравоохранения.
В настоящее время региональная информационная система, которая успешно внедрена и эффективно эксплуатируется в Республике Татарстан и ряде других субъектов России, состоит из следующих решений:

• Единая электронная регистратура и портал пациентов;

- Плановая госпитализация, включая оказание высокотехнологической медицинской помощи;

- Центральный Архив Медицинских Изображений;

- Педиатрический Кластер;

- Кардиологический Кластер;

- Онкологический Кластер;

- Ситуационный центр. Единый портал для построения аналитических и статистических отчетов, организации мониторинга процессов, происходящих в здравоохранении региона.

К системе подключены пятнадцать центров оказания высокотехнологичной медицинской помощи республиканского уровня. В режиме реального времени осуществляется мониторинг, собирается статистика и анализируется использование дорогостоящих ресурсов: кардиохирургических операционных, мощного диагностического оборудования.

В результате внедрения "Диспетчерского центра" повысилась оперативность получения информации о пациенте, затраты времени при обработке документов снизились на $11 \%$, а производительность труда медицинского персонала выросла на 54 \%. Система позволила сократить среднее пребывание 1 больного в высокотехнологичном центре с 13 до 10 дней, что позволило дополнительно госпитализировать в центры около 30000 больных в год.

Проект «Диспетчерский центр»- не столько информационно-аналитический, сколько управленческий. Оценить его прямую экономическую эффективность трудно. Основная задача заключалась в том, чтобы построить экономически эффективную и понятную для людей систему оказания медицинской помощи, на примере Республики Татарстан это получилось.

Одним из главных свойств ИС «Диспетчерский центр» является - полный охват отрасли и возможность расширения на любой бизнес-процесс, который существует или может быть создан в системе здравоохранения региона. Возможность быстрого масштабирования и использование принципа «один ввод данных - многократное использование» позволило создать действительно эффективную систему управления здравоохранением региона и стать незаменимым помощником в медицинских учреждениях при принятии управленческих решений. 